\title{
Use of crosslinkers to inactivate dentin MMPs
}

\section{Seseogullari-Dirihan, $\mathrm{R}$.}

2016-03

Seseogullari-Dirihan , R , Apollonio , F , Mazzoni , A, Tjaderhane , L , Pashley , D , Breschi , L \& Tezvergil-Mutluay , A 2016 , ' Use of crosslinkers to inactivate dentin MMPs ' , Dental Materials , vol. 32 , no. 3 , pp. 423-432 . https://doi.org/10.1016/j.dental.2015.12.012

http://hdl.handle.net/10138/223880

https://doi.org/10.1016/j.dental.2015.12.012

publishedVersion

Downloaded from Helda, University of Helsinki institutional repository.

This is an electronic reprint of the original article.

This reprint may differ from the original in pagination and typographic detail.

Please cite the original version. 


\section{Use of crosslinkers to inactivate dentin MMPs}

\section{R. Seseogullari-Dirihan ${ }^{a}$, F. Apollonio ${ }^{b}$, A. Mazzoni ${ }^{c}$, L. Tjaderhane ${ }^{d}$, D. Pashley ${ }^{e}$, L. Breschi $^{c}$, A. Tezvergil-Mutluay ${ }^{f, g, *}$}

a Finnish Doctoral Program in Oral Sciences (FINDOS) University of Turku, Institute of Dentistry, Turku, Finland

b Universidade Federal Do Ceara, Fortaleza, Brazil

c Department of Biomedical and Neuromotor Sciences, DIBINEM, University of Bologna and IGM-CNR, Unit of

Bologna, Italy

d Department of Oral and Maxillofacial Diseases, University of Helsinki, and Helsinki University Hospital, Helsinki, Finland; Research Unit of Oral Health Sciences, and Medical Research Center Oulu (MRC Oulu), Oulu University Hospital and University of Oulu, Oulu, Finland e School of Dentistry, Georgia Regents University, Augusta, GA, USA

${ }^{\mathrm{f}}$ Department of Restorative Dentistry and Cariology, Adhesive Dentistry Research Group, Institute of Dentistry, University of Turku, Turku, Finland

g Turku University Hospital, TYKS, University of Turku, Turku, Finland

\section{A R T I C L E I N F O}

\section{Article history:}

Received 18 August 2015

Received in revised form

7 December 2015

Accepted 7 December 2015

\section{Keywords:}

Gluteraldehyde

Dentin

Collagen crosslinker

Matrix metalloproteinase

Cycteine cathepsins

\begin{abstract}
A B S T R A C T
Objectives. This study evaluated the endogenous matrix metalloproteinase (MMP) activity of demineralized dentin matrix following 1 or $5 \mathrm{~min}$ pretreatment by various collagen crosslinkers. Generic MMP activity assay, total protein analysis, in situ zymography, gelatin zymography and multiplex bead technology were used to evaluate matrix-bound MMP activity.

Methods. Six different crosslinkers; glutaraldehyde, riboflavin/UVA, riboflavin-5monophospate/UVA, sumac berry extract, grape seed extract, and curcumin were used. Demineralized dentin beams were pretreated with respective crosslinkers for 1 or $5 \mathrm{~min}$. Demineralized dentin beams with no crosslinker pretreatment served as control. The reduction in the total activity of dentin matrices were measured using generic MMP activity assay. Dentin slabs were used for in situ zymography and evaluated by using hydrolysis of self-quenched fluorescein-conjugated gelatin under confocal microscopy. Dentin beam extracts were used for total protein assay and multiplex analysis and powder extracts were used for gelatin zymography.

Results. MMP activity in crosslinker pretreated samples decreased significantly between $21 \%$ and $70 \%$, whereas untreated control samples' activity increased up to $84 \%$. Zymograms confirmed a decrease in the gelatinolytic activity and in the amount of extractable total protein content. Multiplex analysis of extracts of crosslinker-treated dentin showed a reduction in the MMP-8, MMP-2 and MMP-9 release.

Significance. The result of this work suggests that the effect of the crosslinkers is sourcedependent. The use of crosslinkers for as little as 1 min on demineralized dentin can inactivate the endogenous protease activity of dentin matrices.
\end{abstract}

(C) 2015 Academy of Dental Materials. Published by Elsevier Ltd. All rights reserved.

\footnotetext{
* Corresponding author at: Department of Restorative Dentistry and Cariology, Institute of Dentistry, University of Turku, Lemminkaisenkatu 2, Turku FI-20520, Finland. Tel.: +358 23338340.

E-mail address: arztez@utu.fi (A. Tezvergil-Mutluay).
} 


\section{Introduction}

Enzymatic degradation of resin-infiltrated dentin matrices by endogenous proteases results in the loss of stability of resin-dentin bonds created by contemporary adhesives [1]. Matrix metalloproteinases (MMPs), a family of zinc- and calcium-dependent endogenous proteases, are responsible for the turnover of collagen-based tissues [2]. Although MMPs are inactive in mineralized dentin, the application of etching acids in etch-and-rinse or acidic monomers in self-etch adhesives can uncover and activate these proteases [3-6] resulting in progressive loss of collagen from the hybrid layers over time.

To maintain the durability of bonded restorations, use of synthetic MMP inhibitors has been demonstrated to be effective. Chlorhexidine (CHX), an inhibitor of MMP-2, -9 and -8 [7] has been shown to stabilize the resin-dentin interface $[8,9]$. However, recent studies have demonstrated that CHX is only electrostatically bound to dentin [10], and the inhibitory effect of CHX on dentin MMPs may be lost in 1.5-2 years [11].

Biomodification of dentin matrices using collagen crosslinkers such as glutaraldehyde or proanthocyanidin improves the mechanical properties of dentin matrix by enhancing intra- and intermolecular crosslinks of collagen $[12,13]$ and inactivates matrix-bound MMPs [14,15]. However, a wide range of crosslinkers are available, and their specific anti-MMP effects are still not clear. In our previous publication [16] we evaluated the effects of pretreatment of completely demineralized dentin matrix by synthetic or natural crosslinking agents on the loss of dry mass and the liberation of ICTP and CTX telopeptide fragments, as indirect measures of matrix degradation over 3, 7 and 14 days of incubation at $37^{\circ} \mathrm{C}$. In the current study we used the same model and same crosslinking agents to pretreat demineralized dentin for 1 or $5 \mathrm{~min}$. The outcomes that were measured were total MMP activity, total extractable protein, gelatin zymographic activity of dentin extracts and the change in the extractability of MMP-2, -8 and -9 after pretreatment. The tested null hypotheses were that 1 or $5 \mathrm{~min}$ application of collagen crosslinkers does not reduce dentin protease activity, that the collagen crosslinkers do not change the release of proteins from dentin matrix, and that crosslinkers do not inhibit dentin matrix MMPs equally.

\section{Materials and methods}

The source of synthetic and natural collagen crosslinkers and the concentrations used in this study are presented in Table 1. Reagents were purchased from Sigma Chemical (St. Louis, MO, USA) unless otherwise specified. Extracted non-carious human third molars were obtained with informed consent from 18 to 21-year-old patients under a protocol approved by the Ethical Committee of Oulu University, Finland. The teeth were stored at $4{ }^{\circ} \mathrm{C}$ in $0.9 \% \mathrm{NaCl}$ containing $0.02 \% \mathrm{NaN}_{3}$ to prevent microbial growth, and were used within 1 month after extraction.

\subsection{Generic MMP assay}

A generic colorimetric MMP assay (Sensolyte Generic MMP assay, Anaspec, San Jose, CA, USA) was used to determine if crosslinker could inhibit the total matrix-bound endogenous MMPs in dentin. The enamel and superficial dentin of human molars were removed with a low-speed saw (Isomet, Buehler Ltd., Lake Bluff, IL, USA) under water cooling. Dentin specimen with dimensions $0.4 \mathrm{~mm} \times 4 \mathrm{~mm} \times 4 \mathrm{~mm}$ was sectioned from the mid-coronal dentin (one square per tooth). Dentin squares were completely demineralized in $10 \% \mathrm{H}_{3} \mathrm{PO}_{4}$ for $24 \mathrm{~h}$ at $4{ }^{\circ} \mathrm{C}$ and rinsed in distilled water at $4{ }^{\circ} \mathrm{C}$ for $1 \mathrm{~h}$. After demineralization, the intrinsic total MMP activity of each specimen was determined by incubating them in $200 \mu \mathrm{L}$ of chromogenic

Table 1 - Synthetic and natural crosslinking reagent and their composition, solvent, chemical content and manufacturers are shown with their concentrations used in this study.

\begin{tabular}{|c|c|c|c|c|c|}
\hline Group & Composition & Solvent & Description & Manufacturer & Lot No \\
\hline GA1 & 1\% Glutaraldehyde (v/v) & \multirow[t]{2}{*}{ Distilled water } & Protein crosslinker & \multirow[t]{2}{*}{ Merck, Finland } & \multirow[t]{2}{*}{ S5334503-928 } \\
\hline GA5 & $5 \%$ Glutaraldehyde (v/v) & & $\mathrm{OHC}\left(\mathrm{CH}_{2}\right)_{3} \mathrm{CHO}$ & & \\
\hline GS1 & $1 \%$ Grape seed extract (w/v) & \multirow[t]{2}{*}{ Hot water } & \multirow{2}{*}{$\begin{array}{l}\text { Vitis vinifera, Natural } \\
\text { proanthocyanidin source }\end{array}$} & Mega-natural gold & \multirow[t]{2}{*}{$13682503-01$} \\
\hline GS5 & $5 \%$ Grape seed extract (w/v) & & & $\begin{array}{l}\text { grape seed extract } \\
\text { CA, USA }\end{array}$ & \\
\hline R1 & $0.1 \%(-)$ Riboflavin (w/v) & \multirow[t]{2}{*}{ Distilled water } & Enzyme cofactor & Sigma-Aldrich, & \multirow[t]{3}{*}{ OSOM1704Y } \\
\hline R5 & $\begin{array}{l}0.5 \%(-) \text { Riboflavin (w/v) } \\
\text { with UVA light } 365 \mathrm{~nm} \text {, } \\
7 \mathrm{~mW} / \mathrm{cm}^{2}\end{array}$ & & $\mathrm{C}_{17} \mathrm{H}_{20} \mathrm{~N}_{4} \mathrm{O}_{6}$ & Finland & \\
\hline $\mathrm{S}$ & $10 \%$ Sumac $(w / v)$ & Hot water & $\begin{array}{l}\text { Rhus coriaria, Natural } \\
\text { proanthocyanidin source }\end{array}$ & $\begin{array}{l}\text { Collected natural } \\
\text { seed }\end{array}$ & \\
\hline RP1 & $\begin{array}{l}0.1 \% \\
\text { Riboflavin-5-phosphate } \\
(\mathrm{w} / \mathrm{v} \text { ) with UVA light } \\
370 \mathrm{~nm}, 3 \mathrm{~mW} / \mathrm{cm}^{2}\end{array}$ & Distilled water & $\mathrm{C}_{17} \mathrm{H}_{20} \mathrm{~N}_{4} \mathrm{P}$ & $\begin{array}{l}\text { Sigma-Aldrich, } \\
\text { Finland }\end{array}$ & 24887210 \\
\hline $\begin{array}{l}\text { CR20 } \\
\text { CR200 }\end{array}$ & $\begin{array}{l}20 \mu \mathrm{M} \text { Curcumin (w/v) } \\
200 \mu \mathrm{M} \text { Curcumin (w/v) }\end{array}$ & $\begin{array}{l}0.2 \% \text { Ethanol in } \\
\text { distilled water }\end{array}$ & $\begin{array}{l}\text { (1E,6E)-1,7-Bis(4-hydroxy-3- } \\
\text { methoxyphenyl)-1,6- } \\
\text { heptadiene-3,5-dione }\end{array}$ & LKT LAB & $458-37-7$ \\
\hline
\end{tabular}


thiopeptide substrate and assay buffer, in a 96-well plate for $60 \mathrm{~min}$ at $25^{\circ} \mathrm{C}$. After $60 \mathrm{~min}$, the specimens were removed from the wells, and baseline MMP activity of each specimen was measured at $412 \mathrm{~nm}$ (Synergy HT; BioTek Instruments, Winooski, VT, USA). After baseline measurements, the specimens were rinsed free of MMP assay substrate and distributed to different groups in such a way that the mean baseline activity of each group was similar ( $n=5$ /group). The specimens were then dipped in $300 \mu \mathrm{L}$ of water (for controls) or respective crosslinkers for 1 or $5 \mathrm{~min}$, rinsed, blot-dried and incubated in fresh chromogenic substrate and assay buffer in the 96 -well plate for $60 \mathrm{~min}$ at $25^{\circ} \mathrm{C}$. The groups were: Controls (CM) pretreated with distilled water; GA1, treated with $1 \%$ glutaraldehyde; GA5, treated with $5 \%$ glutaraldehyde; GS1, treated with 1\% grape seed extract; GS5, treated with $5 \%$ grape seed extract; $R 1$, treated with $0.1 \%$ riboflavin activated by Ultraviolet-A light (UVA; Philips, Hamburg, Germany; $\lambda=370 \mathrm{~nm}$ at $3 \mathrm{~mW} / \mathrm{cm}^{2}$ ); R5, treated with $0.5 \%$ riboflavin activated by UVA; CR20, treated with $20 \mu \mathrm{M}$ curcumin; CR200, treated with $200 \mu \mathrm{M}$ curcumin; S, treated with $10 \%$ sumac berry extract; RP1, treated with $0.1 \%$ riboflavin-5-phosphate activated by UVA (Table 1). After $60 \mathrm{~min}$ of incubation in the buffer, the specimens were removed from the incubation buffer and the MMP activity was reassessed as described above. The total MMP activity was expressed as a percentage of the untreated baseline level of each sample to determine the relative inhibition or activation.

The data from all groups were compared for normality (Kolmogorov-Smirnov test) and equality of variance (modified Levine test). When these statistical assumptions were valid, the differences in the percentage inhibition of MMPs in different groups were analyzed first using two-way ANOVA and Tukey's tests at $\alpha=0.05$ (IBM SPSS v.21, NY, USA). Since the interactions between the groups were significant, one-way ANOVA and Tukey's tests was used to evaluate the differences within each time point.

\subsection{Zymographic analysis}

One hundred extracted human third molars were ground free of enamel and pulpal soft tissue and roots were removed. Coronal dentin powder was prepared by pulverizing liquid nitrogen-frozen dentin crowns with a steel mortar/pestle (Reimiller, Reggio Emilia, Italy). Dentin powder was demineralized by stirring the powder with $10 \mathrm{wt} \% \mathrm{H}_{3} \mathrm{PO}_{4}$ for $10 \mathrm{~min}$ at $4{ }^{\circ} \mathrm{C}$, which was then neutralized with $70 \mu \mathrm{L} 4 \mathrm{~N} \mathrm{NaOH}$ and centrifuged. Mineralized dentin powder was used as a control.

Analysis of gelatinolytic activity in the dentin powder was performed using gelatin zymography in accordance with Mazzoni et al. [3]. Dentin powder (100 $\mathrm{mg}$ in each group) was divided into 12 groups that were treated with $100 \mu \mathrm{L}$ crosslinker solutions for 1 or $5 \mathrm{~min}$ described in Table 1 , and with the generic MMP assay above. In addition, mineralized dentin powder (MIN) was used as a negative control. After pretreatment, samples were rinsed twice with $200 \mu \mathrm{L}$ distilled water and centrifuged to remove the supernatant. Samples were re-suspended in $1.8 \mathrm{~mL}$ extraction buffer $(50 \mathrm{mM}$ Tris-HCl, pH 6, containing $5 \mathrm{mM} \mathrm{CaCl}_{2}, 100 \mathrm{mM} \mathrm{NaCl}, 0.1 \%$ Triton $\mathrm{X}-100,0.1 \%$ non-ionic detergent $\mathrm{P}-40,0.1 \mathrm{mM} \mathrm{ZnCl}_{2}, 0.02 \%$ $\mathrm{NaN}_{3}$ ) for $24 \mathrm{~h}$ at $4{ }^{\circ} \mathrm{C}$ under constant stirring. Each specimen were then sonicated for $20 \mathrm{~min}$ and centrifuged for $20 \mathrm{~min}$ at $4{ }^{\circ} \mathrm{C}(12,000 \mathrm{rpm})$. Aliquots of samples including protein extracts were concentrated by means of a centrifugal concentrator device $(10,000-\mathrm{kDa}$ cut-off, Vivaspin Sartorius Stedim Biotech, Goettingen, Germany) for $30 \mathrm{~min}$ at $20^{\circ} \mathrm{C}(10,000 \mathrm{rpm})$ until the volume was reduced to a volume of $100 \mu \mathrm{L}$. The Bradford assay was performed to determine total protein concentrations of dentin extracts. Sixty microgram of dentin protein aliquots were diluted in Laemmli sample buffer at a 4:1 ratio and subjected to electrophoresis under non-reducing conditions in $10 \%$ sodium dodecyl sulfate-polyacrylamide (SDS-PAGE) gel containing $1 \mathrm{mg} / \mathrm{mL}$ gelatin which had been fluorescently labeled with MDPF by the method of O'Grady et al. [17]. A SDS-PAGE standard, mixture of ten recombinant proteins, (Dual Color Standards, Bio-Rad), was used as molecular weight markers. After electrophoresis, the gels were washed for $30 \mathrm{~min}$ twice in $2.5 \%$ Triton X-100 with agitation, and incubated in activation solution $(50 \mathrm{mmol} / \mathrm{L}$ Tris- $\mathrm{HCl}$, $\left.5 \mathrm{mM} \mathrm{CaCl}_{2}, 1 \mathrm{mM} \mathrm{ZnCl}_{2}, 150 \mathrm{mM} \mathrm{NaCl}, \mathrm{pH} 7.4\right)$ for $48 \mathrm{~h}$ at $37^{\circ} \mathrm{C}$. To evaluate gelatinolytic activity, gels were monitored with long-wavelength UV light (Gel Doc XR System, Bio-Rad,) to reveal nonfluorescent bands cleared of gelatin by enzymes.

\subsection{In situ zymography}

Fourteen freshly extracted intact human third molars were used. The enamel and superficial dentin of each tooth were removed with use of a low-speed saw under water cooling. Dentin disks $0.5 \mathrm{~mm}$ thick were sectioned from the midcoronal dentin. Each dentin disk was glued to a microscope slide with cyanoacrylate glue. The disk surfaces were ground with 600-grit wet silicon-carbide paper, and dentin surface was etched for $10 \mathrm{~s}$ with $10 \% \mathrm{H}_{3} \mathrm{PO}_{4}$ and rinsed for $20 \mathrm{~s}$ with distilled water. Each etched dentin disk was treated with $50 \mu \mathrm{L}$ of the relevant crosslinker solutions (Table 1) for 1 or $5 \mathrm{~min}$. Mineralized and demineralized dentin disks without crosslinker pretreatment were used as controls. After crosslinking pretreatment, the dentin surface was blot-dried with absorbent paper. A self-quenched fluorescein-conjugated gelatin was used as the MMP substrate (E-12055, Molecular Probes, Eugene, OR, USA). The substrate was prepared from a $1 \mathrm{~mL}$ stock solution of DQ-gelatin (DQ-gelatin, E12055; Molecular Probes, Eugene, OR, USA). An anti-fading agent (Mounting Medium with Dapi H-1200, Vectashield, Vector Laboratories LTD, Cambridgeshire, UK) and fluorescein-conjugated gelatin were diluted 1:1:8 in the dilution buffer $\left(\mathrm{NaCl} 150 \mathrm{mM}, \mathrm{CaCl}_{2} 5 \mathrm{mM}\right.$, Tris- $\mathrm{HCl} 50 \mathrm{mM}$, pH 8.0). Fifty microliter of the fluorescentgelatin solution was spread on top of each sample and covered with a coverslip. Samples were incubated in dark in a $100 \%$ relative humidity chamber at $37^{\circ} \mathrm{C}$. To observe hydrolysis of quenched fluorescein-conjugated gelatin substrate that resulted from gelatinolytic activity, each sample was examined under a multi-photon confocal microscope, 488 and $530 \mathrm{~nm}$ with excitation and emission wavelengths, respectively (Zeiss, LSM 780, Carl Zeiss, Oberkochen, Germany). Optical sections of $85 \mu \mathrm{m}$ thickness were acquired at different focal planes, and the stacked images were analyzed, quantified, and processed with ZEN 2010 software (Carl Zeiss, Jena, Germany). The images were obtained at 0 and $48 \mathrm{~h}$ after incubation. 


\subsection{Measurement of total extractable total protein}

The measurement of total extractable protein in the dentin matrix extracts was performed using phosphoric acid demineralized dentin beams as described above. After pretreatment with crosslinkers, demineralized dentin beams were rinsed with distilled water and incubated in $0.5 \mathrm{~mL}$ extraction buffer $(50 \mathrm{mM}$ Tris- $\mathrm{HCl}, \mathrm{pH} 6$, containing $5 \mathrm{mM}$ $\mathrm{CaCl}_{2}, 100 \mathrm{mM} \mathrm{NaCl}, 0.1 \%$ Triton $\mathrm{X}-100,0.1 \%$ non-ionic detergent $\mathrm{P}-40,0.1 \mathrm{mM} \mathrm{ZnCl} 2,0.02 \% \mathrm{NaN}_{3}$ ) for $72 \mathrm{~h}$ at $4{ }^{\circ} \mathrm{C}$ under constant stirring. The demineralized beams dipped in water for 1 or $5 \mathrm{~min}$ served as control. Total protein concentrations of the extracts were determined by using Bradford method. The measurements were carried out according to the manufactures instructions (Bio-Rad, Hercules, CA, USA). A $1-50 \mu \mathrm{g} / \mathrm{mL}$ series of bovine serum albumin (BSA) standards $(50 \mu \mathrm{L})$, and $50 \mu \mathrm{L}$ aliquots of supernatant from each beam for each time-point were analyzed. After 5 min of incubation, the absorbance was measured using a spectrophotometer (Shimadzu Scientific Instrument Inc., Columbia, MD, USA) at $595 \mathrm{~nm}$ wavelength. A linear standard curve was prepared by plotting the average reading for each BSA standard vs. its concentration in $\mu \mathrm{g} / \mathrm{mL}$. The standard curve was used to determine the protein concentration of each sample. Data were analyzed by using two-way ANOVA and Tukey's post-hoc test $(p<0.05)$.

\subsection{Multiplex bead-based immunoassay}

Dentin specimens with dimensions $4 \mathrm{~mm} \times 6 \mathrm{~mm} \times 1 \mathrm{~mm}$ were sectioned from the mid-coronal dentin ( 5 beams/group). The specimens were completely demineralized in 10\% phosphoric acid as described above and transferred to individually labelled containers and placed in a vacuum desiccator containing dry silica beads for $72 \mathrm{~h}$. The initial dry mass was measured with an analytical balance (XP6 Microbalance, Mettler Toledo, Hightstown, NJ, USA). After the dry mass measurement, the specimens were rehydrated for $1 \mathrm{~h}$ in distilled water and dipped in the crosslinker solutions (Table 1) for 1 or $5 \mathrm{~min}$. After crosslinker treatment, the beams were washed three times with $200 \mu \mathrm{L}$ of distilled water, and placed in corresponding polypropylene tubes with $0.5 \mathrm{~mL}$ extraction buffer ( $50 \mathrm{mM}$ Tris-HCl, pH 6, containing $5 \mathrm{mM} \mathrm{CaCl}_{2}, 100 \mathrm{mM}$ $\mathrm{NaCl}, 0.1 \%$ Triton X-100, 0.1\% non-ionic detergent P-40, $0.1 \mathrm{mM}$ $\mathrm{ZnCl}_{2}, 0.02 \% \mathrm{NaN}_{3}$ ) for $72 \mathrm{~h}$ at $4{ }^{\circ} \mathrm{C}$ under constant stirring. Demineralized dentin with no crosslinker treatment was used as a control.

The extractable dentinal MMPs in each group were measured using the Fluorescent Microsphere Immunoassay method using human MMP-MAP multiplex kit (R\&D Systems, Inc., Minneapolis, MN, USA). The extract supernatants from each beam and reagents were pipetted into wells in duplicate, following the manufacturer's instructions, and incubated for $2 \mathrm{~h}$ at room temperature (RT). After washing away any unbound substances, antibodies to MMP-2, -8 , and -9 were added to each well and incubated for $1 \mathrm{~h}$ at $25^{\circ} \mathrm{C}$. Following a wash to remove any unbound biotinylated antibody, streptavidin-phycoerythrin conjugate (streptavidin-PE) was added to each well and incubated for $0.5 \mathrm{~h}$ at RT. After the final wash to remove unbound streptavidin-PE, the microparticles were resuspended in buffer and measured using a multiplex analyzer (Bio-Plex ${ }^{\mathrm{TM}} 200$ Systems, Bio-Rad, Austin, TX, USA) and associated software. The instrument calculated the mean and the median fluorescence intensity from 100 microspheres of each set. Standard curves were fitted ( 5 parameters fitting program) and concentrations calculated by Milliplex Analyst software (Millipore Co., Billerica, MA, USA). Data were analyzed by using ANOVA and Tukey's post-hoc test $(p<0.05)$.

\section{Results}

\subsection{Inhibition of MMP activity}

The results of the generic total-MMP activity screening assay are shown in Fig. 1. The control group showed an $84.1 \pm 15.8 \%$ increase in total MMP activity compared to the demineralized baseline level. All crosslinker pretreatment groups showed significant reductions in the total MMP activity compared to control $(p<0.05)$. After 1 min of pretreatment, the highest inhibition was $64 \%$ compared to the baseline activity observed at $5 \%$ grape seed group, which corresponds to $177 \%$ reduction compared to the activity level of control group. The highest inhibition after $5 \mathrm{~min}$ of crosslinking was observed at $1 \%$ grape seed group with $69 \%$ inhibition, corresponding to a $181 \%$ inhibition compared to control. The lowest inhibition was obtained using 1\% glutaraldehyde at GA1 and $0.1 \%$ riboflavin after $1 \mathrm{~min}$ crosslinking, showing $21 \%$ and $23 \%$ inhibition compared to baseline level, and $78 \%$ and $121 \%$ respectively compared to control activity level.

\subsection{Effect of crosslinkers on extractable total protein}

The effect of crosslinkers on the total extractable proteins is shown in Fig. 2. After $72 \mathrm{~h}$ of extraction, the non-crosslinked control samples released $40 \mu \mathrm{g}$ protein/mg dentin dry weight, whereas crosslinker-treated demineralized dentin groups showed extractable protein levels of $10-35 \mu \mathrm{g}$ protein/mg dry dentin or $20-80 \%$ compared to controls. After $1 \mathrm{~min}$ of crosslinking, the extractable protein in GA5, GS1, R1, R5, CR20 and S groups were significantly lower compared to control $(p<0.05)$. After 5 min pretreatment, all crosslinker groups showed significantly lower extractable protein compared to control $(p<0.05)$. However, no significant differences were found among different crosslinkers $(p>0.05)$.

\subsection{Zymographic analysis}

Zymograms of gelatinolytic activities after 1 and $5 \mathrm{~min}$ crosslinker treatments are shown in Fig. 3A and B, respectively. Demineralized dentin (DEM) exhibited MMP-2 pro- and active forms (72 and $66 \mathrm{kDa}$, respectively), and pro-and active form MMP-9 (95-86 kDa) (Fig. 3), whereas mineralized dentin powder showed lower enzymatic activity (MIN, Fig. 3). Gelatinolytic activity was observed as faint or disappeared of MMP-2 active-forms $(66 \mathrm{kDa})$, and fainter bands of MMP-9 activeforms $(86 \mathrm{kDa})$ in crosslinker groups compared with controls. Reduced MMP-9 activity was obvious following both 1 and 5 min crosslinker treatment, especially in GS1, GS5, R1, R5, RP1 and $\mathrm{S}$ compared to control. 


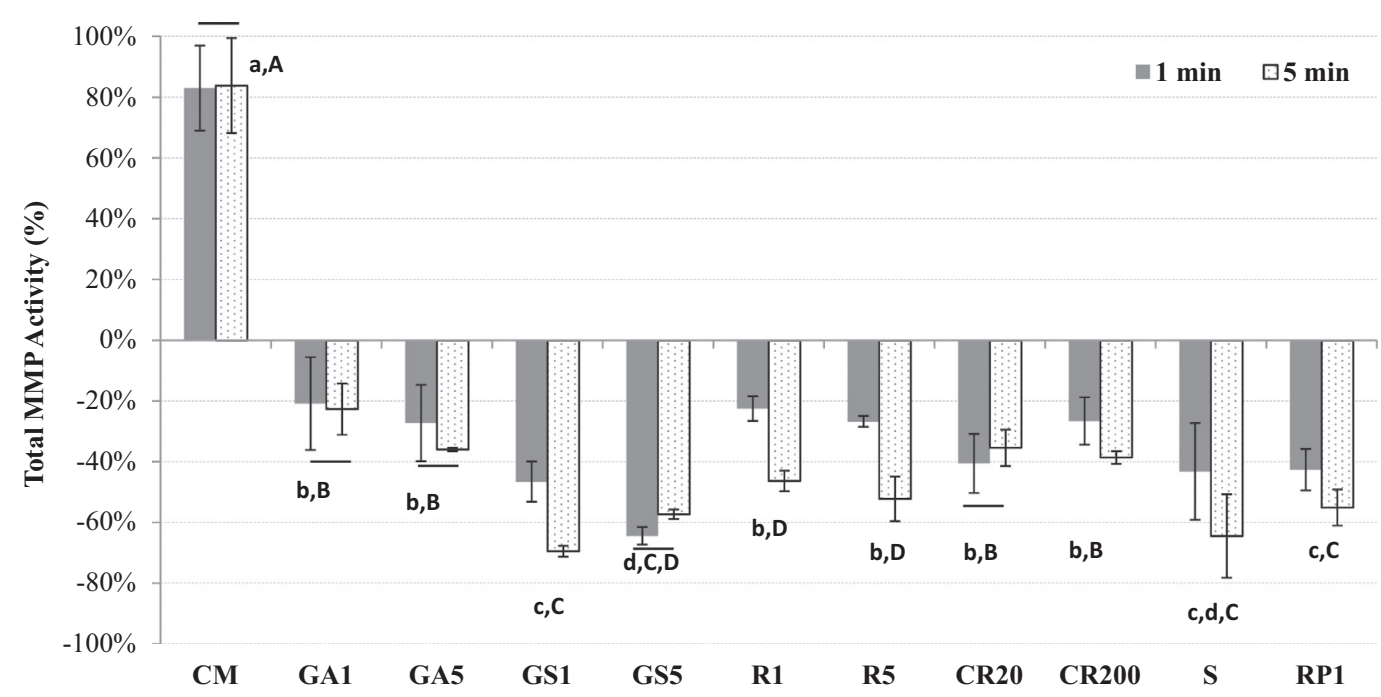

Fig. 1 - The bar chart shows \% of total MMP activity in the control at the positive side, and \% inhibition of the dentin MMPs after collagen crosslinker pretreatment or no-treatment control. The activity is expressed as the \% change compared to baseline level. (Abbreviations correspond to; glutaraldehyde (GA), grape-seed extract (GS), sumac (S), curcumin (CR), riboflavin/UV (R), riboflavin-5-phosphate/UV (RP1) and untreated control (CM). Groups labeled with different letters are significantly different $(p<0.05)$. The $1 \mathrm{~min}$ crosslinker pretreatment groups with the same lower case letter were not statistically different $(p>0.05)$. The 5 min crosslinker pretreatment groups with the same upper case letter are not statistically different $(p>0.05)$. For each crosslinker material or concentration, as well as the control preincubation period, columns connected by a solid black bar were not statistically different from one another $(p>0.05)$.

\subsection{In situ zymography}

To evaluate whether the gelatinase enzymes remained bound to the dentin matrix, in situ zymography was performed. As can be seen in Fig. 4, there is a clear difference in gelatinolytic activity between crosslinker treated and non-treated demineralized dentin. In mineralized dentin (MIN), weak activity was observed both initially and after incubation (Fig. 4A and B). Non-crosslinked demineralized dentin matrix (DEM) had the highest enzyme activity indicated by the highest intensity of

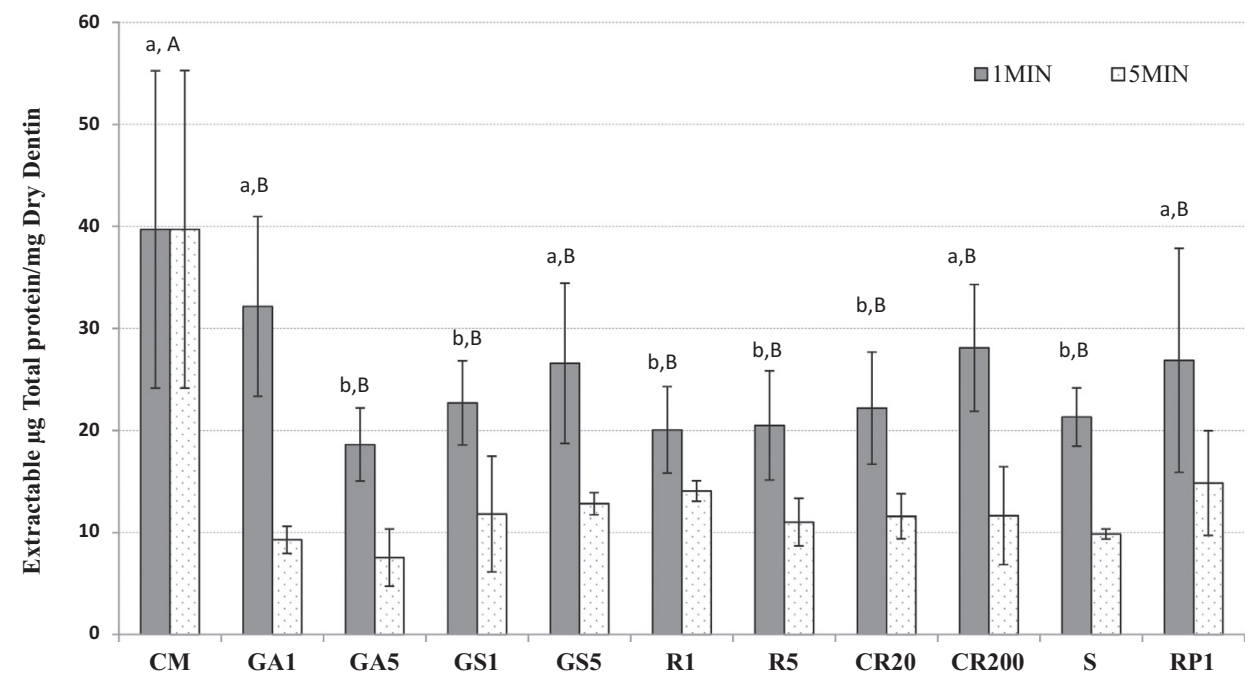

Fig. 2 - Extractable protein from various crosslinker treated demineralized dentin beams (72 $\mathrm{h}$ of extraction). The group incubated in extraction media (CM) with no crosslinker pretreatment served as the control $(n=5)$. Abbreviations correspond to; glutaraldehyde (GA), grape-seed extract (GS), sumac (S), curcumin (CR), riboflavin/UV (R), riboflavin-5-phosphate/UV (RP1) and untreated control (CM). Groups identified by different letters are significantly different $(p<0.05)$. One minute pretreatment groups with the same lower case letter were not statistically significant $(p>0.05)$. Five minute pretreatment groups with the same upper case letter were not statistically significant $(p>0.05)$. For each crosslinker material or concentration, as well as the control preincubation period, columns connected by a solid black bar were not statistically significant from one another $(P>0.05)$. 


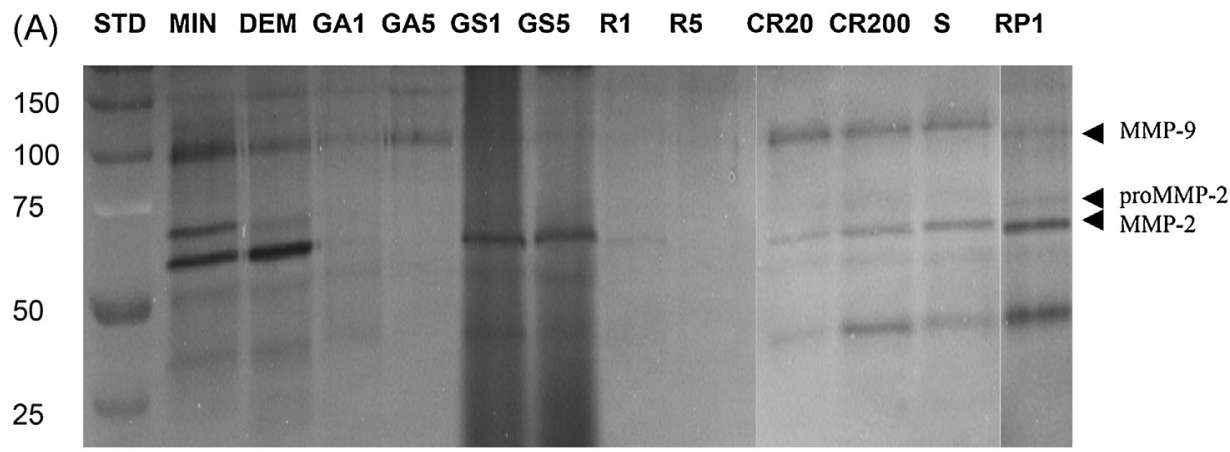

$\begin{array}{llllllllll}\text { (B) STD MIN DEM GA1 GA5 GS1 GS5 } & \text { R1 } & \text { R5 } & \text { CR20 } & \text { CR200 } & S & \text { RP1 }\end{array}$

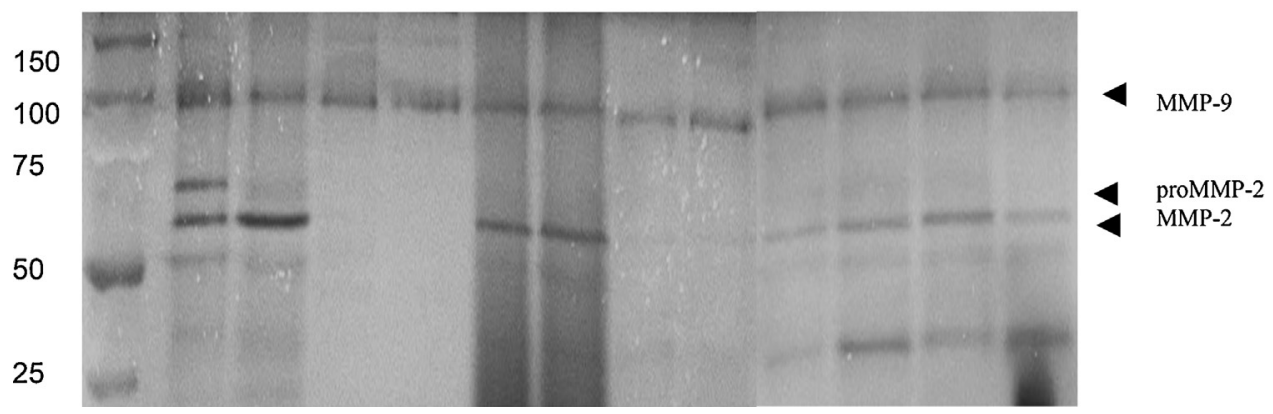

Fig. 3 - Zymographic analysis of dentin powder treated with or without crosslinkers for 1 min (A) or 5 min (B). MMP-2 proand active-form (72- and 66-kDa respectively) and MMP-9 (92-86-kDa) are labeled with arrows. Lane 1: Molecular masses, expressed in $\mathrm{kDa}$, are reported in the standard lane (STD). Lane 2: MIN, mineralized dentin powder showing the presence of MMP-2 pro- and active-form (72- and 66-kDa, respectively) MMP-9 (95 kDa) in which faint activity was recorded. Lane 3: DEM, demineralized dentin with $10 \%$ phosphoric acid (control 2) showed intense activity related to the MMP-2 proform and MMP-9. Lanes 4 and 5: Demineralized dentin powder after treatment with $1 \%$ and $5 \%$ glutaraldehyde (GA) respectively, reduced MMP-2 pro- and active-form and of MMP-9 compared with the demineralized dentin. Lanes 6 and 7: Treatment of demineralized dentin powder with $1 \%$ and $5 \%$ grape seed extract (GS) respectively, had a decrease in the activity of MMP-2 and MMP-9 compared with the demineralized dentin. Lanes 8 and 9: Treatment of demineralized dentin powder with 0.1\% and $0.5 \%$ riboflavin (R), respectively, almost totally inhibited both MMP-2 and -9 activities. Lanes 10 and 11 : Treatment of demineralized dentin powder with 20 and $200 \mu \mathrm{M}$ curcumin (CR), respectively, caused partial inhibition of the 72-kDa MMP-2 proform and complete inactivation of the 86-kDa MMP-9, in addition a fainter molecular band of approximately $40 \mathrm{kDa}$ was detected. Lane 12: Treatment of demineralized dentin powder with $10 \%$ sumac (S), similarly, decreased both active and pro- form of MMP-2 and MMP-9, in addition a fainter molecular band of approximately $40 \mathrm{kDa}$ was detected. Lane 13: Treatment of demineralized dentin powder with $0.1 \%$ riboflavin-5-phosphate (RP1) resulted in the partial inactivation of the 66-kDa MMP-2 active and pro- form and inhibition of the 86-kDa MMP-9. As similar to CR (Lanes 10 and 11 ), a fainter molecular band of approximately $40 \mathrm{kDa}$ was detected.

green fluorescence (Fig. 4B, DEM). Similar to the gelatin zymography results, less gelatinolytic activity was detected for the crosslinked experimental groups (Fig. 4B). Gelatinolytic activity was mainly observed within dentin tubules and slightly on exposed collagen surfaces. The gelatinolytic activity was stronger in dentin tubules before crosslinker treatment than after crosslinker treatment.

3.5. Quantification of MMP-2, -8 and -9 using multiplex bead-based immunoassay

The amount of extractable MMP-2,-8 and -9 in controls vs. crosslinked specimens are presented in Fig. 5. The control specimens showed 25-fold higher levels of MMP-2 (Fig. 5A) compared to MMP-8 (Fig. 5B). After $1 \mathrm{~min}$ of crosslinking, all groups showed a significant decrease in MMP-2 extractability compared to control $(p<0.05)$, which decreased further with 5 min crosslinking.

The amount of MMP-8 extracted from control sample was only $4 \%$ as much as MMP-2 and decreased slightly after $1 \mathrm{~min}$ of crosslinking, but the reduction was not significant $(p>0.05)$ except for GA1, GS5, R5 and CR200 groups, which showed a significant reduction after 1 min crosslinking $(p<0.05)$. After 5 min of crosslinking, all crosslinked groups showed between $40 \%$ and $60 \%$ reductions in MMP-8 extractability which was significantly different compared to control group $(p<0.05)$.

MMP-9 extractability from all groups was significantly lower compared to MMP-2 levels. The control groups released $17 \mathrm{pg} / \mathrm{mg}$ dentin, and after $1 \mathrm{~min}$ crosslinking, all crosslinker groups showed significantly lower quantities $(p<0.05)$. 

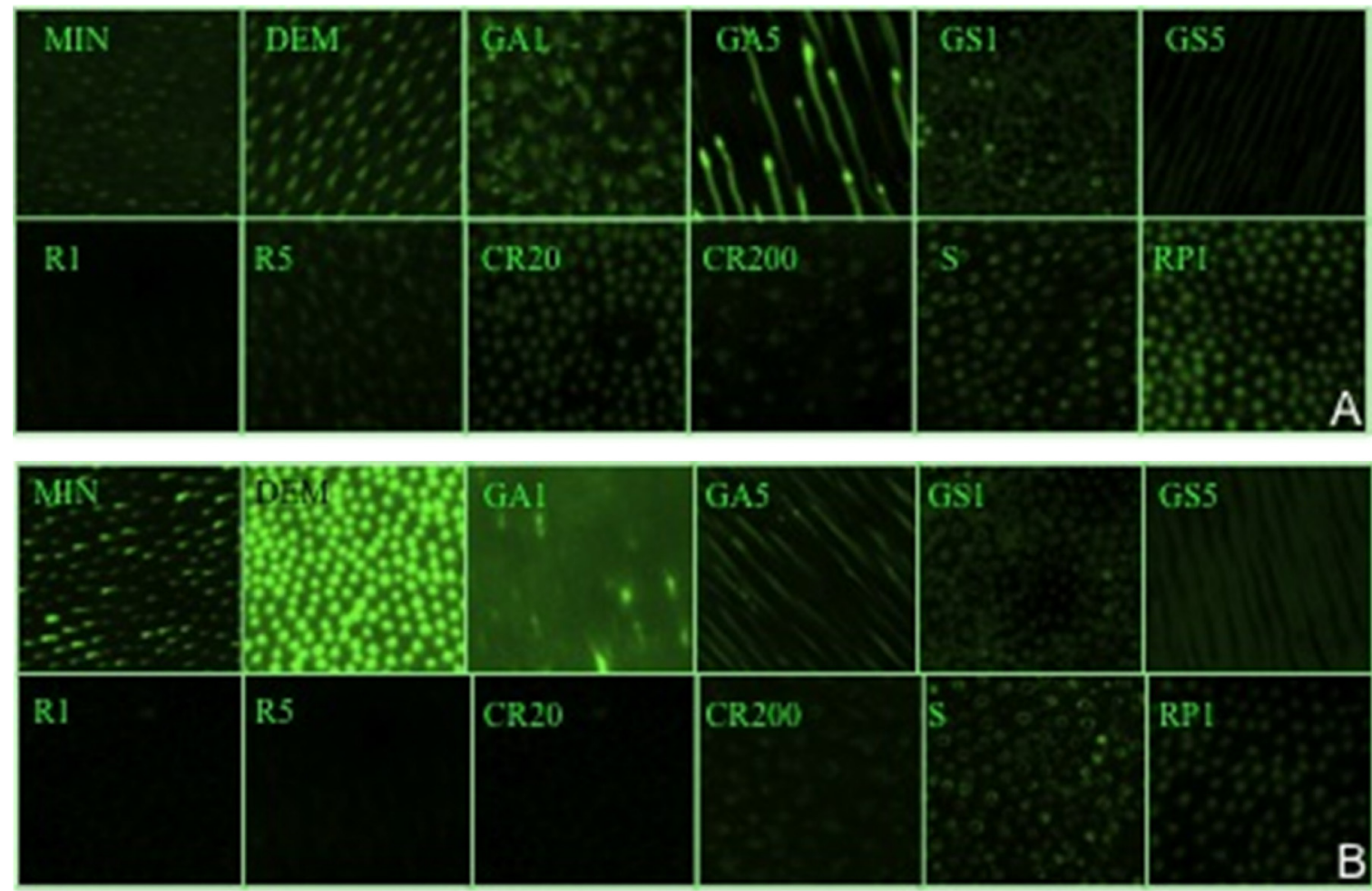

Fig. 4 - (A) In situ zymography of group with crosslinker following pretreatment $(0 \mathrm{~h})$ and (B) $48 \mathrm{~h}$ after incubation. Green fluorescence shows gelatinolytic activity localized in dentin surface. Demineralized dentin treated with various crosslinkers and mineralized dentin (negative control) were incubated with quenched fluorescein-labeled gelatin for $48 \mathrm{~h}$ at $37^{\circ} \mathrm{C}$; MIN, mineralized (control1) showed less gelatinolytic activity compared with the demineralized dentin; DEM, demineralized (control2)was observed as higher fluorescence density after incubation; GA1, demineralized treated with $1 \%$ glutaraldehyde; GA2, demineralized treated with $5 \%$ glutaraldehyde; GS1, demineralized treated with $1 \%$ grape seed extract; GS2, demineralized treated with $5 \%$ grape seed extract; R1, demineralized treated with $0.1 \%$ riboflavin; R2, demineralized treated with $0.5 \%$ riboflavin; CR1, demineralized treated with $20 \mu \mathrm{M}$ curcumin; CR2, demineralized treated with $200 \mu \mathrm{M}$ curcumin; S, demineralized treated with (w/v) $20 \%$ sumac extract; RP1, demineralized treated with $0.1 \%$

riboflavin-5-phosphate; RP1, demineralized treated with $0.5 \%$ riboflavin-5-phosphate. All treated groups showed a decrease of gelatinolytic activity after incubation. (For interpretation of the color information in this figure legend, the reader is referred to the web version of the article.)

\section{Discussion}

Collagen crosslinking agents have been reported to increase the resistance of dentin collagen matrix to degradation $[14,18,19]$. To date, glutaraldehyde is the most commonly used synthetic cross-linker, while proanthocyanidin is frequently reported in dental research as a natural cross-linker [19-22]. In the present study, we compared the effect of various plantderived natural as well as synthetic cross-linkers on the MMP activity of collagen matrix.

Detection of MMPs activity was accomplished through the use of gelatin zymography, in situ zymography and enzyme activity assays. Additionally, multiplex bead-based assay was used to quantify the degradative enzymes by simultaneously evaluating MMP-8, MMP-2 and MMP-9 levels as collagenolytic, gelatinolytic and telopeptidase MMPs detected in dentin [9].

Notably, all investigated crosslinkers showed different potentials of reducing dentin protease activity, which were significantly lower compared to no-treatment controls. These results require the rejection of the first null hypothesis.

The highest statistically significant inhibition of total MMP activity was observed using grape seed extract for 1 or $5 \mathrm{~min}$, followed by sumac (S) and by $0.1 \%$ riboflavin $5^{\prime}$-phosphate (RP1), and $0.5 \%$ riboflavin after 5 min of crosslinking.

Sumac; Rhus coriaria, which grows wild in the region from the Mediterranean to the Middle East, is widely used as a medicinal herb in those regions, particularly for wound healing [23]. Previous studies have demonstrated strong antioxidant activity of sumac extracts $[24,25]$ and suggest that extracts are a rich source of hydrolyzable tannins, with gallic acid being the major polyphenol [25]. The tannins are well recognized for their affinity to proteins, as well as the metal ions. Their multiple phenolic hydroxyl groups can form stable complexes with many metal ions [26].

In this study, the total protein concentrations of extracts of control and crosslinked specimens were measured to evaluate the relative efficacy of these agents in crosslinking proteins in general. The results show a decrease of $25-50 \%$ in the amount 

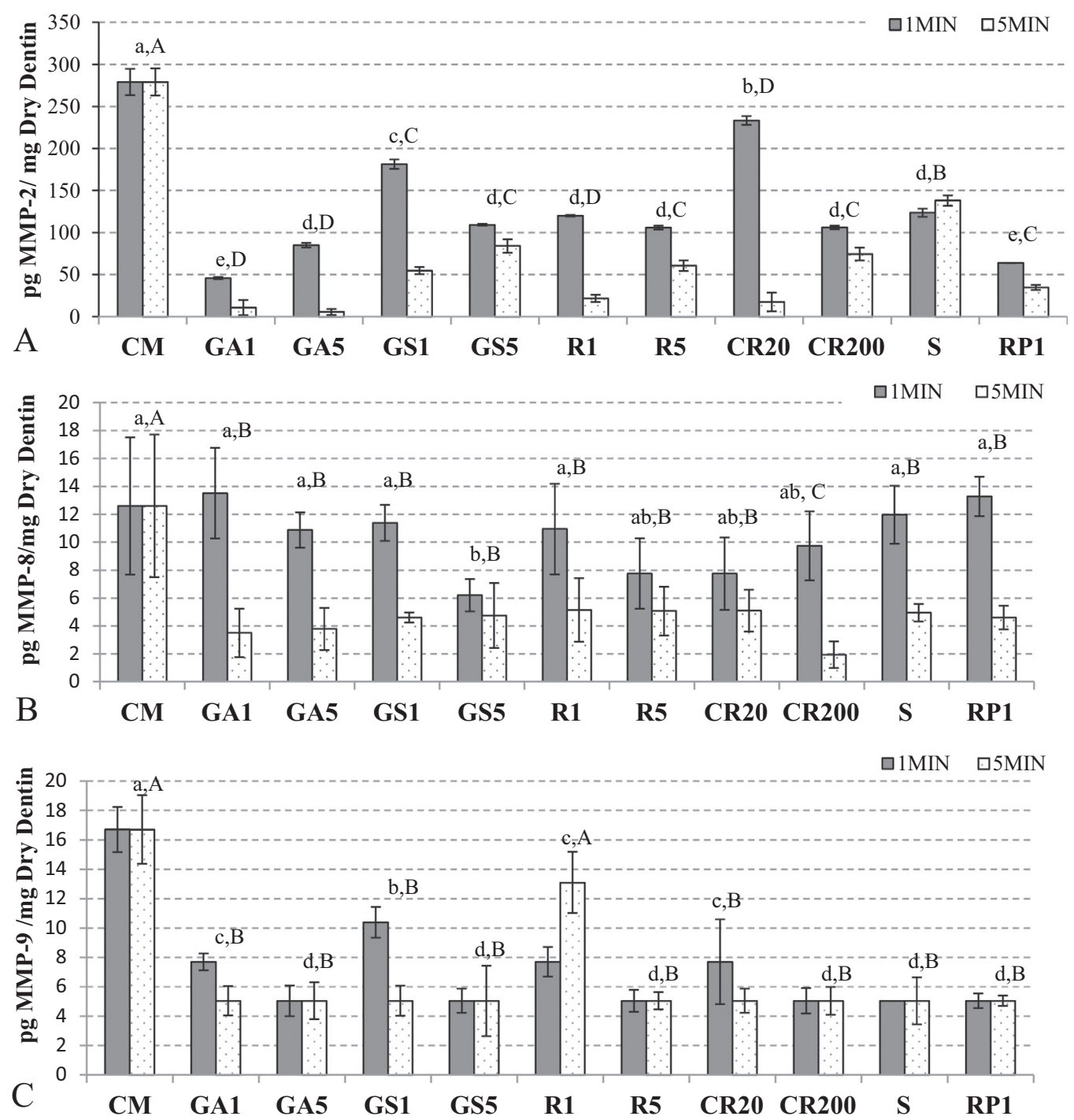

Fig. 5 - Extractable MMP-2 (A), MMP-8 (B) and MMP-9 (C) amount (pg/mg dry dentin) after 1 or 5 min of crosslinking.

of extractable protein after $1 \mathrm{~min}$ of crosslinking, and an almost $70-80 \%$ decrease after 5 min crosslinking. The higher protein concentration of extracts of non-crosslinked controls is interpreted as the accumulation of solubilized collagen and released non-collagen products due to MMP activity. It is likely that pretreatment of insoluble dentin matrix by cross-linking agents would produce considerable additional intermolecular crosslinking between adjacent collagen molecules, decreasing the size exclusion cut-off of the collagen. The recent work by Toroian et al. [27] and Takahashi et al. [28] on the sizeexclusion characteristics of type I collagen, show that small molecules (up to $6 \times 10^{3} \mathrm{Da}$ ) can diffuse in and out of collagen fibrils, but that molecules over $48 \times 10^{3} \mathrm{Da}$ are excluded from entering or leaving insoluble type I collagen. We speculate that cross-linking demineralized dentin matrix lowers the permeability of soluble molecules, trapping them within the collagen fibrils.

Additionally, the results of multiplex bead analysis confirmed a significant decrease in extractable MMP-2 and MMP-9, even after as short as $1 \mathrm{~min}$ of crosslinking. After $5 \mathrm{~min}$ of crosslinking MMP-2, MMP-8 and MMP-9 were significantly less extractable compared to untreated controls. This confirms the speculation that reduced protein extraction in crosslinked groups is correlated with crosslinking non-collagen proteins and collagen matrix, as well as crosslinking of proteases which caused their inactivation.

The binding of polyphenols to collagen and proteases is thought to be mediated by hydrogen bonding between phenolic hydroxyl residues of polyphenol and free amino groups $\left(-\mathrm{NH}_{2}-\right)$ of collagen, or by forming ionic bonds between collagen side chains [29-31]. Proline residues are geometrically preferred polyphenol binding sites, and their interaction consists of a face-to-face stacking of aromatic polyol groups onto proline residues. MMP-9 has several proline dimers, while MMP-2 has only one [32]. However, Strek et al. [33] reported that both enzymes were inhibited to a similar extent by polyphenol-rich extracts. They explained the inactivation mechanism of gelatinases by as being dependent on the proline content, as well as on the amino acid sequences of these enzymes [33]. 
In the present study, UVA-irradiated $0.1 \%$ or $0.5 \%$ riboflavin inactivated the total MMPs $46 \%$ and $52 \%$, respectively, within 5 min of crosslinking. When $0.1 \%$ riboflavin $5^{\prime}$-phosphate was used for crosslinking, it inactivated total matrix bound MMPs $55 \%$, whereas the MMP activity increased $84 \%$ in the untreated control. Others have reported that the photo-induced application of $0.1 \%$ riboflavin to demineralized dentin increased the bond strength of dentin by stabilizing collagen, and decreased the collagen degradation after bacterial collagenase challenge $[34,35]$. Riboflavin is a photosensitizer that stimulates the formation of reactive oxygen species when irradiated by UVA light. The release of reactive oxygen species can induce the formation of covalent cross-links through oxidation by UVA [36]. Cova et al. [34] indicated that the degradation of dentin collagen can be reduced by application of UVA-activated riboflavin, and MMPs activity can be inactivated by through direct cross-linking of MMPs or by strengthening the collagen fibrils through cross-linking.

Gelatin zymography has been used for identification of the presence and activity of gelatinases MMP-2 and -9 (gelatinase $\mathrm{A}$ and $\mathrm{B}$ ), are also known as $72 \mathrm{kDa}$ gelatinase and $92 \mathrm{kDa}$ gelatinase, respectively. Both gelatinases have three repeat fibronectin domains which are responsible for the ability of MMP-2 and MMP-9 to bind to gelatin, collagen I and IV, and laminin [37]. In present study, gelatinolytic activities were detected by gelatin zymography. Mazzoni et al. [3] was first to report the presence of both endogenous MMP-2 and -9 are present in latent forms (as pro-enzymes) in mature sound teeth and the presence of several forms of both proforms (92 kDa), and activated MMP-9 $(86 \mathrm{kDa})$ in dentin. Previously, gelatin zymography was used demonstrate MMP-2 and -9 activities [38]. In the current study, proteases were observed in 66 and $86 \mathrm{kDa}$ bands representing active MMP-2 and -9 , and the 72 and $92 \mathrm{kDa}$ bands for proMMP-2 and -9 , respectively. Following demineralization, the use of crosslinkers as a pretreatment agent decreased the activity of these gelatinases as shown in the fainter 66 and $86 \mathrm{kDa}$ bands.

Most MMPs are secreted as pro-enzymes (zymogens). Once these are activated by proteolytic cleavage, they are converted to their smaller active enzymes [39]. In gelatin zymography, both active and pro-MMPs gelatinolytic activity can be revealed because their molecular structures are distorted by the polyacrylamide gel although quantitation of MMP activity is difficult. In situ zymography is another effective method to explore the localization of the gelatin-degrading enzymes in the demineralized dentin matrix, and their relative activities before and after crosslinking [40]. This technique is also used for identification of particular enzymatic activity in physiological and/or pathological conditions. In this study, in situ zymography was performed on mineralized and demineralized dentin to screen the effect of crosslinkers compared to untreated controls. Activated MMP -2 and -9 in dentin have the ability to digest gelatin in untreated controls, whereas all crosslinker treated groups were inhibited to varying degrees by crosslinkers, with $5 \mathrm{~min}$ exposures inhibiting better than 1 min exposures. In contrast, the enzymatic activity for nontreated controls increased during incubation. The findings of the study confirm that the positive effect of short pretreatment with collagen crosslinkers on inactivation of gelatinases (especially for MMP-2 and -9) in demineralized dentin. Interestingly,
MMP-8 was much more difficult for crosslinkers to inactivate (Fig. 5B). This result requires rejection of the third test null hypothesis. Because MMP-2 and - 9 contain triple fibronectin type-II like domains, unlike MMP-8 that is devoid of these domains, it is tempting to suggest that those triple domains may make MMP-2 and -9 more susceptible to crosslinking than MMP-8.

The results of this study indicate that 1 min pretreatments of acid-etched dentin by many different crosslinking agents can inactivate MMP-2, -8 and -9 in a clinically relevant time. Further research is required to determine if such inactivation is permanent over time.

\section{Acknowledgements}

This study was supported by grant \#8126472 from the Academy of Finland to AT-M (PI), EVO funding of Turku University Hospital to AT-M (PI) and by FINDOS Mobility Grant awarded to Dr. Seseogullari Dirihan as part of her PhD thesis. The authors wish to thank Mr. Aurelio Valmori for photographical assistance. The authors do not have a financial interest in products, equipment, and companies cited in the manuscript.

\section{REFERE N C ES}

[1] Liu Y, Tjäderhane L, Breschi L, Mazzoni A, Li N, Mao J, et al. Limitations in bonding to dentin and experimental strategies to prevent bond degradation. J Dent Res 2011;90:953-68.

[2] Visse R, Nagase H. Matrix metalloproteinases and tissue inhibitors of metalloproteinases: structure, function, and biochemistry. Circ Res 2003;92:827-39.

[3] Mazzoni A, Mannello F, Tay FR, Tonti GA, Papa S, Mazzotti G, Di Lenarda R, et al. Zymographic analysis and characterization of MMP-2 and -9 forms in human sound dentin. J Dent Res 2007;86:436-40

[4] Mazzoni A, Pashley DH, Nishitani Y, Breschi L, Tjäderhane L, Toledano M, et al. Reactivation of inactivated endogenous proteolytic activities in phosphoric acid-etched dentin by etch-and-rinse adhesives. Biomaterials 2006;27:4470-6.

[5] Nishitani Y, Yoshiyama M, Wadgaonkar B, Breschi L, Mannello F, Mazzoni A, et al. Activation of gelatinolytic/collagenolytic activity in dentin by self-etching adhesives. Eur J Oral Sci 2006;114:160-6.

[6] Tezvergil-Mutluay A, Mutluay MM, Seseogullari-Dirihan R, Agee KA, Key WO, Scheffel DLS, et al. Effect of phosphoric acid on the degradation of human dentin matrix. J Dent Res 2013;92:87-91.

[7] Gendron R, Grenier D, Sorsa T, Mayrand D. Inhibition of the activities of matrix metalloproteinases 2, 8 and 9 by chlorhexidine. Clin Diagn Lab Immunol 1999;6(3):437-9.

[8] Carrilho MR, Geraldeli S, Tay FR, de Goes MF, Carvalho RM, Tjäderhane L, et al. In vivo preservation of hybrid layer by chlorhexidine. J Dent Res 2007;86:529-33.

[9] Tjäderhane L, Nascimento FD, Breschi L, Mazzoni A, Tersariol IL, Geraldeli S, et al. Optimizing dentin bond durability: control of collagen degradation by matrix metalloproteinases and cysteine cathepsins. Dent Mater 2013;29:116-35.

[10] Kim J, Uchiyama T, Carrilho M, Agee KA, Mazzoni A, Breschi $\mathrm{L}$, et al. Chlorhexidine binding to mineralized versus demineralized dentin. Dent Mater 2010;26:771-8. 
[11] Sadek FT, Braga RR, Muench A, Liu Y, Pashley DH, Tay FR. Ethanol wet-bonding challenges current anti-degradation strategy. J Dent Res 2010;89:1499-504.

[12] Bedran-Russo AK, Pereira PN, Duarte WR, Drummond JL, Yamauchi M. Application of crosslinkers to dentin collagen enhances the ultimate tensile strength. J Biomed Mater Res B: Appl Biomater 2007;80:268-72.

[13] Al-Ammar A, Drummond JL, Bedran-Russo AK. The use of collagen cross-linking agents to enhance dentin bond strength. J Biomed Mater Res B Appl Biomater 2009;91:419-24.

[14] Tezvergil-Mutluay A, Mutluay MM, Agee KA, Seseogullari-Dirihan R, Hoshika T, Cadenaro M, et al. Carbodiimide cross-linking inactivates soluble and matrix-bound MMPs, in vitro. J Dent Res 2012;91:192-6.

[15] Mazzoni A, Angeloni V, Apolonio FM, Scotti N, Tjaderhane L, Tezvergil-Mutluay Di Lenarda R, et al. Effect of carbodiimide (EDC) on the bond stability of etch-and-rinse adhesive systems. Dent Mater 2013;29:1040-7.

[16] Seseogullari-Dirihan R, Mutluay MM, Vallittu P, Pashley DH, Tezvergil-Mutluay A. Effect of pretreatment with collagen crosslinkers on dentin protease activity. Dent Mater 2015;31:941-7.

[17] O'Grady RL, Nethery A, Hunter N. A fluorescent screening assay for collagenase using collagen labeled with 2methoxy-2,4-diphenyl-3(2H)-furanone. Anal Biochem 1984;140:490-4.

[18] Koide T, Daito M. Effects of various collagen crosslinking techniques on mechanical properties of collagen film. Dent Mater J 1997;16:1-9.

[19] Walter R, Miguez PA, Arnold RR, Pereira PN, Duarte WR, Yamauchi M. Effects of natural cross-linkers on the stability of dentin collagen and the inhibition of root caries in vitro. Caries Res 2008;42:263-8.

[20] Han B, Jaurequi J, Tang BW, Nimni ME. Proanthocyanidin A natural crosslinking reagent for stabilizing collagen matrices. J Biomed Mater Res 2003;65A:118-24.

[21] Bedran-Russo AK, Castellan CS, Shinohara MS, Hassan L, Antunes A. Characterization of biomodified dentin matrices for potential preventive and reparative therapies. Acta Biomater 2011;7:1735-41

[22] Liu Y, Dusevich V, Wang Y. Proanthocyanidins rapidly stabilize the demineralized dentin layer. J Dent Res 2013;92:746-52.

[23] Sezik E, Tabata M, Yeşilada E. Traditional medicine in Turkey Folk medicine in northeast Anatolia. J Ethnopharmacol 1991;35:191-6.

[24] Zalacain A, Alonso GL, Prodanov M, Carmona M. Determination of the tanning capacity of Rhus coriaria L. extract and its antioxidant activity. J Soc Leath Tech Ch 2000;84:212-5.
[25] Kosar M, Bozan B, Temelli F, Baser KHC. Antioxidant activity and phenolic composition of sumac (Rhus coriaria L.) extracts. Food Chem 2007;103:952-9.

[26] The Merck Index. In: Budovari S, editor. White House Station, NJ: Merck Co Inc.; 1996. p. 1550.

[27] Toroian D, Lim JE, Price PA. The size exclusion characteristics of type I collagen: implications for the role of noncollagenous bone constituents in mineralization. J Biol Chem 2007;282:22437-47.

[28] Takahashi M, Nakajima T, Tagami J, Scheffel DLS, Carvalho RM, Mazzoni A, et al. The size-exclusion characteristics of type I collagen in dentin matrices. Acta Biomater 2013;9:9522-8.

[29] Tu ST, Lollar RM. A concept of the mechanism of tannage by phenolic substances. J Am Leather Chem Ass 1950;45:324-46.

[30] Pankhurst KGA. Monolayer studies of tanning reactions. In: Surface phenomena in chemistry and biology. London: Pergamon Press; 1958. p. 100-16.

[31] Hagerman AE, Butler LG. The specificity of proanthocyanidin-protein interactions. J Biol Chem 1981;256:4494-7.

[32] Baxter NJ, Lilley TH, Haslam F, Williamson MP. Multiple interactions between polyphenols and a salivary prolinerich protein repeat result in complexation and precipitation. Biochemistry 1997;36:5566-77.

[33] Strek M, Gorlach S, Podsedek A, Sosnowska D, Koziolkiewicz M, Hrabec Z, et al. Procyanidin oligomers from Japanese quince (Chaenomeles japonica) fruit inhibit activity of MMP-2 and MMP-9 metalloproteinases. J Agric Food Chem 2007;55:6447-52.

[34] Cova A, Breschi L, Nato F, Ruggeri AJ, Carrilho M, Tjäderhane L, et al. Effect of UVA-activated riboflavin on dentin bonding. J Dent Res 2011;90:1439-45.

[35] Fawzy A, Nitisusanta L, Iqbal K, Daood U, Beng LT, Neo J. Characterization of riboflavin-modified dentin collagen matrix. J Dent Res 2012;91:1049-54.

[36] Snibson GR. Collagen cross-linking: a new treatment paradigm in corneal disease-a review. Clin Exp Ophthalmol 2010;38:141-53.

[37] Nagase H. Activation mechanisms of matrix metalloproteinases. J Biol Chem 1997;378:151-60.

[38] Snoek-van Beurden PA, Von den Hoff JW. Zymographic techniques for the analysis of matrix metalloproteinases and their inhibitors. Biotechniques 2005;38:73-83.

[39] Brinckerhoff CE, Matrisian LM. Matrix metalloproteinases: a tail of a frog that became a prince. Nat Rev Mol Cell Biol 2002;3:207-14.

[40] Mazzoni A, Nascimento FD, Carrilho M, Tersariol I, Papa V, Tjaderhane L, et al. MMP activity in the hybrid layer detected with in situ zymography. J Dent Res 2012;91: 467-72. 